\title{
The inappropriate use of carotid endarterectomy
}

\author{
Henry J.M. Barnett
}

ß See related article page 455

$\mathrm{N}$ o single procedure has been the focus of more large randomized trials testing standard medical treatment against surgical benefit than carotid endarterectomy (CE). Primary results and secondary analyses have been published from 4 large trials, 2 involving patients with focal symptoms related to carotid stenosis, ${ }^{1,2}$ and 2 involving asymptomatic patients. ${ }^{3,4}$ More than 10000 individuals accepted random assignment to therapy, trusting that randomization, careful follow-up and sophisticated analyses would answer for them and for future patients how best to use CE to achieve a stroke-free life. These 4 trials have provided unambiguous clinical guidelines for the appropriate use of carotid endarterectomy. ${ }^{5}$ Are the lessons from these trials being properly applied by the right doctors to the right patients?

The study by James Kennedy and colleagues ${ }^{6}$ published in this issue provides disturbing evidence that, in many Canadian centres, guidelines derived from 25 years of meticulous research are not necessarily being put into practice. Using a previously refined "appropriateness scale," Kennedy and colleagues studied the records of 3167 CEs done over 2 years in Canada's 4 western provinces. Only half $(52.3 \%)$ met the criteria for appropriateness, and adherence to these critera ranged widely, from $78.2 \%$ in Saskatchewan to $46.0 \%$ in British Columbia. The remaining procedures were done for "uncertain" or "inappropriate" reasons, the "inappropriate" use varying from $5.8 \%$ in Saskatchewan to $13.0 \%$ in British Columbia, with an overall rate of $10.3 \%$. The fact that almost half of the CEs were performed for uncertain or inappropriate indications means that many patients are being exposed to nontrivial operative risks without a realistic expectation of benefit.

Kennedy and colleagues also found that the biennial rate of CE performance in individual hospitals varied from 8 to 429 , with a median of 135 ; interestingly, fewer CEs were performed for inappropriate reasons in low-volume sites than in high-volume sites. Although this better selection of surgical candidates is admirable, one must also be aware that previous studies have reported that low-volume surgeons in low-volume hospitals have more perioperative complications of stroke and death than do high-volume surgeons in institutions making extensive use of CE. ${ }^{78} \mathrm{Al}$ though the current study does not provide details of hospital complication rates, one can expect that these rates will be higher in low-volume centres. It is not sufficient for CE to be done for appropriate reasons only. Surgeons must have the necessary expertise to ensure low complication rates. Low-volume hospitals with high complication rates would be wise to refer appropriate patients for endarterectomy to hospitals with more experienced surgeons.

The randomized trials of the past 25 years have given us guidelines about who should and should not undergo CE and have clarified the limits of allowable perioperative complication rates. The indications, contraindications and acceptable operative risk levels should be known by all referring doctors. ${ }^{5}$ Table 1 summarizes, for different patient groups, the expected number needed to treat with $\mathrm{CE}$ to prevent 1 stroke in 2 years. It assumes that the operating surgeon's complication rate will not exceed $6 \%$ for symptomatic patients and that patients with other life-threatening illnesses will not undergo the procedure. Special caution must be exercised for patients with only moderate $(50 \%-$ $69 \%$ ) stenosis who are women or who have had ocular symptoms only. They will benefit only if they also have a recognizably high vascular risk profile. No data exist to give credence to the use of $\mathrm{CE}$ when the stenosis on the side of the symptoms is below $50 \%$. Unhappily, some of these lowest-risk patients turned up in the Kennedy study.

Two large trials involving asymptomatic patients have presented evidence that there is modest benefit favouring CE in subjects with stenosis but no symptoms, provided that highly skilled surgeons are involved and that complication rates are below 3\%. Even with this low operative complication rate, the number needed to treat to prevent 1 stroke in 2 years is $83 .{ }^{5}$ In the 2 large trials involving a total of nearly 4500 patients, the annual stroke and death

\begin{tabular}{lc}
\hline $\begin{array}{l}\text { Table 1: Estimates of number needed to treat (NNT) with } \\
\text { carotid endarterectomy to prevent } \mathbf{1} \text { stroke in } \mathbf{2} \text { years by age } \\
\text { and degree of stenosis }\end{array}$ \\
\hline Patient group & NNT \\
\hline Symptomatic* & 6 \\
$\geq 70 \%$ stenosis, age $<75 \mathrm{yr}$ & 3 \\
$\geq 70 \%$ stenosis, age $\geq 75 \mathrm{yr}$ & 15 \\
$50 \%-69 \%$ stenosis & No benefit \\
$<50 \%$ stenosis & \\
Asymptomatic $†$ & 83 \\
$>60 \%$ stenosisł & \\
\hline
\end{tabular}

*Allowable complication rate $<6 \%$.

†Allowable complication rate $>3 \%$.

$\ddagger$ Breakdown by decile of stenosis unknown. 
rate after $\mathrm{CE}$ was $1 \%$, versus $2 \%$ among those without CE. What we do not know is whether this $2 \%$ could be reduced by a strictly supervised regimen of best modern medical care, including control of blood pressure, diabetes mellitus, lipids and cigarette smoking, along with appropriate ASA therapy. A trial of CE versus tightly controlled (as opposed to standard) medical care is one of the last remaining major trials still required to complete our knowledge of the role of CE in stroke prevention in asymptomatic patients.

As the absolute benefit for any intervention decreases (as is the case for asymptomatic compared with symptomatic patients) and the complication risks increase, the hazards of the intervention become more clinically relevant. One case series of 1214 endarterectomies performed in asymptomatic patients reported a perioperative complication rate of 4.4\%. It was estimated that if these 1214 subjects had a similar prognosis to the control group of the large randomized trials, then no benefit in favour of surgery would have been detectable for 4 years, if at all. During that 4-year period more strokes would have accumulated in the surgical than in the medical group. ${ }^{9}$ Recent US Medicare and other administrative reports underscore the fact that the allowable limits of surgical complication are being exceeded too often for asymptomatic subjects. ${ }^{10}$ When allowable complication rates are exceeded, CE becomes a risk rather than a benefit to asymptomatic subjects.

The evidence used to weigh the risk and benefit for reducing the hazards of carotid stenosis may change over the next few years as randomized trial data emerge on the evolving technology of carotid stenting. So far, about 1500 symptomatic patients have been randomly assigned to either stenting or CE in large trials now in progress in North America, Europe and Australia..11, Until stenting has been shown by evidence-based methodology to be as effective and as safe as CE in preventing stroke, this potentially exciting alternative remains unproven and experimental.

Meanwhile, how can we ensure that our patients are offered CE at acceptable risk for appropriate indications? First, physician and patients must have access to the results of annually conducted, totally independent audits of the 30-day complication rates of the institutions and surgeons performing CE. The evaluation of invasive coronary artery therapies stimulated by Naylor and others ${ }^{13,14}$ ensured that many audits of success and failure are available on institutional Web sites, yet arms-length audits for results of CE are rarely available. A reasonable portion of the health care budget is expended on these public hospitals, and patients and referring physicians deserve disclosure of these rates in order to make evidence-based decisions. Second, candidates for CE should know that they will be treated by a team that includes a skilled surgeon and a medical stroke expert who can provide the necessary medical and surgical surveillance required before and after CE. This is equivalent to the team approach that is the standard of care for patients with coronary artery disease who are candidates for surgical management.

Patients who were candidates for CE committed themselves to clinical trials to improve outcomes for themselves and future patients. The results clearly delineate who should undergo CE and under what circumstances. The study by Kennedy and colleagues demonstrates that we are not always practising the lessons we learn. Both referring physicians and surgeons should evaluate their practices in order to offer the most appropriate care, and institutions must be forthright with their CE performance records.

Henry Barnett is Scientist Emeritus at the Robarts Research Institute and Professor Emeritus at the University of Western Ontario, London, Ont.

Competing interests: None declared.

\section{References}

1. Barnett HJM, Taylor DW, Eliasziw M, Fox AJ, Ferguson GG, Haynes RB, et al, for the North American Symptomatic Carotid Endarterectomy Trial Collaborators. Benefit of carotid endarterectomy in symptomatic patients with moderate and severe stenosis. N Engl F Med 1998;339:1415-25.

2. European Carotid Surgery Trialists' Group. Randomized trial of endarterectomy for recently symptomatic carotid stenosis: final results of the $\mathrm{MRC} \mathrm{Eu}-$ ropean Carotid Surgery Trial (ECST). Lancet 1998;351:1379-87.

3. Executive Committee for the Asymptomatic Caroid Atherosclerosis Study. Endarterectomy for asymptomatic carotid artery stenosis. FAMA 1995;273:1421-8.

4. MRC Asymptomatic Carotid Surgery Trial (ACST) Collaborative Group. Prevention of disabling and fatal strokes by successful carotid endarterectomy in patients without recent neurological symptoms: randomised controlled trial. Lancet 2004:363:1491-502.

5. Barnett HJM, Meldrum HE, Eliasziw M, for the North American Symptomatic Carotid Endarterectomy Trial (NASCET) Collaborators. The appropriate use of carotid endarterectomy. CMA7 2002;166(9):1169-79.

6. Kennedy J, Quan H, Ghali WA, Feasby TE. Variations in rates of appropriate and inappropriate carotid endarterectomy for stroke prevention in 4 Canadian provinces. CMA7 2004;171(5):455-9.

7. Feasby TE, Quan H, Ghali WA. Hospital and surgeon determinants of carotid endarterectomy outcomes. Arch Neurol 2002;59:1877-81.

8. Findlay JM, Nykolyn L, Lubkey TB, Wong JH, Mouradian M, Senthilselvan A. Auditing Carotid Endarterectomy: a regional experience. Can 7 Neurol Sci 2002;29:326-32.

9. Barnett HJM, Meldrum H, Thomas DJ, Eliasziw M. Treatment of asymptomatic arteriosclerotic carotid artery disease. In: Barnett HJM, Bogousslavsky J, Meldrum H, editors. Ischemic stroke. Advances in neurology. Vol 92. Philadelphia: Lippincott, Williams and Wilkins; 2003 . p. 319-28.

10. Kresowick TF, Brazler D, Karp HR, Hemann RA, Hendel ME, Grund SL, et al. Multistate utilization, processes, and outcomes of carotid endarterectomy. 7 Vasc Surg 2001;33:227-35.

11. Hobson RW. Update on the Carotid Revascularization Endarterectomy vs. Stent Trial (CREST) Protocol. 7 Am Coll Surg 2002;194(1 Suppl):S9-14.

12. Ringleb PA, Kunze A, Allenberg JR, Hennerici MG, Jansen O, Maurer PC, et al. The Stent-supported Percutaneous Angioplasty of the Carotid Artery vs. Endarterectomy Trial. Cerebrovasc Dis 2004;18:66-8.

13. Naylor CD. What is appropriate care? N Eng 7 Med 1998;338:1918-20.

14. Hux JE, Naylor CD. Are the marginal returns of coronary artery surgery smaller in high-rate areas? The Steering Committee of the Provincial Adult Cardiac Care Network of Ontario. Lancet 1996;348:1202-7.

Correspondence to: Dr. Henry J.M. Barnett, 14865 Concession 7, King City ON L7B 1K4; fax 905 859-5450; hjmb@sympatico.ca 